\title{
Mediações on-line em cursos de educação a distância os professores de língua portuguesa em questão
}

\author{
FLAMINIO DE OLIVEIRA RANGEL \\ Universidade Federal de São Paulo, \\ Diadema, SP, Brasil
}

HELOISA ALBUQUERQUE COSTA Universidade de São Paulo, São Paulo, SP, Brasil

CRISTIANE CAGNOTO MORI DE-ANGELIS Pontifícia Universidade Católica de São Paulo, São Paulo, SP, Brasil

ROBERTA LOMBARDI MARTINS Pontifícia Universidade Católica de São Paulo, São Paulo, SP, Brasil

\section{RESUMO}

$\mathrm{O}$ artigo discute os tipos de mediação on-line desenvolvidos em fóruns do curso "Práticas de Leitura e Escrita na Contemporaneidade" por assessores técnico-pedagógicos (ATP) e outros profissionais com formações distintas e de diferentes áreas e níveis de atuação da rede pública estadual de São Paulo. Partindo do pressuposto de que a formação universitária dos participantes levaria a uma performance otimizada por parte daqueles que tiveram uma formação básica em língua portuguesa, questiona-se se os professores com formação nessa área dominariam mais os conteúdos e, portanto, fariam uma mediação nos fóruns de qualidade mais desejável do que os professores de outras formações. A análise das respostas, com base em elementos desejáveis e não desejáveis, ao não confirmar essa hipótese, retoma, em outro patamar, os conceitos de mediação on-line e letramentos múltiplos. 


\section{ONLINE MEDIATIONS IN COURSES OF DISTANCE EDUCATION: PORTUGUESE LANGUAGE TEACHERS IN QUESTION}

\section{ABSTRACT}

This paper discusses the different kinds of online mediation developed in the "Course of Practices of Reading and Writing in the Contemporaneity" forums by technical-pedagogical assessors (TPA) and other professionals with diverse disciplinary backgrounds, from different areas and levels of interventions in the public schools of São Paulo. Based on the assumption that the university training of the participants would lead to an optimized performance as opposed to those that had a basic training in the portuguese language, the article asks whether the teachers with training in this area would master the contents better and, therefore, have a more qualified intervention in the forums than the teachers with other backgrounds. The analysis of the answers from expected and unwanted elements, not confirming this hypothesis, recovers in another level, the concepts of online mediation and multiple literacies.

\section{KEYWORDS}

online mediation; teaching of portuguese language; multiple literacies; distance education.

\section{MEDIACIONES ONLINE EN CURSOS DE EDUCACIÓN A DISTANCIA: PROFESORES DE LENGUA PORTUGUESA ENCUESTIÓN}

RESUMEN

Este artículo debate los tipos de mediación online desarrollados en fórums del curso "Prácticas de Lectura y Escritura en la Contemporaneidad" por colaboradores técnico-pedagógicos (ATP) y otros profesionales con formaciones distintas y de diferentes sectores y niveles de actuación en la red pública del estado de São Paulo. Partiendo de la suposición de que la instrucción universitaria de los participantes llevaría a una performance optimizada por parte de aquellos que tuvieron una formación básica en lengua portuguesa, se cuestiona si los mismos dominarían mejor los contenidos y, por lo tanto, podrían mediar con más calidad en los fórums, en relación a los profesores con otras formaciones. El análisis de las respuestas a partir de elementos deseables y no deseables, al no confirmar esta hipótesis, retoma, en otro nivel, los conceptos de mediación online y de literacidades múltiples.

\section{PALABRAS CLAVE}

mediación online; enseñanza de lengua portuguesa; literacidades múltiples; educación a distancia. 


\section{APRESENTAÇÃO: A QUESTÃO-PROBLEMA}

Esta investigação teve como objetivo descrever e discutir os tipos de mediação on-line desenvolvidos em fóruns do curso "Práticas de Leitura e Escrita na Contemporaneidade", ou doravante simplesmente Práticas, por assessores técnico-pedagógicos ${ }^{1}$ (ATPs), professores coordenadores $(\mathrm{PCs}),{ }^{2}$ supervisores e professores, de disciplinas distintas, que atuam na educação básica nível II e do ensino médio da rede pública estadual de São Paulo.

Partimos do pressuposto de que as concepções enunciativo-discursivas de linguagem (Bakhtin, 1997) e sociointeracionista de aprendizagem e mediação (Vigotski, 1991,2001), estruturantes do curso, permitiriam sugerir que as formações e as práticas profissionais anteriores desses atores configurariam as práticas de leitura e escrita que eles apresentariam no início do curso.

Isso poderia indicar uma performance otimizada, na mediação dos fóruns on-line, por aqueles que tivessem uma formação básica em língua portuguesa, dada a atividade profissional de lidar com os gêneros discursivos em situações de comunicação, nas diversas esferas de atividade humana (Bakhtin, 1997).

Disso emergiu a questão-problema: os ATPs com formação na área de língua portuguesa dominariam mais o uso dos gêneros discursivos em situações de comunicação, assim como os aspectos teóricos dessa prática e, portanto, fariam uma mediação nos fóruns de qualidade mais desejável do que os ATPs com outras formações?

Aparentemente simples de ser respondida, essa pergunta adquiriu uma dimensão mais complexa quando a colocamos em relação a dois conceitos-chave: a noção de letramentos múltiplos (Barbosa, 2007) e a de mediação on-line (Barbosa et al., 2004).

$\mathrm{Na}$ direção do primeiro conceito, entendemos que o termo letramento - ainda no singular - serviu, quando de sua introdução no vocabulário das ciências humanas, para demarcar a diferença entre a aprendizagem do código escrito, o domínio da tecnologia de ler e de escrever (a alfabetização) e a aprendizagem dos usos da escrita em práticas sociais diversas (Soares, 1998).

O surgimento de um novo termo é decorrência do reconhecimento de uma nova realidade, cujas práxis já não são mais suficientemente definidas e explicadas pelo aparato conceitual existente. De modo semelhante ao que ocorreu no fim da década de 1980, no fim dos anos de 1990 e nos primeiros anos do novo milênio surgiram novas práticas sociais que exigiram um redimensionamento do termo letramento. $\mathrm{Na}$ verdade, trata-se da necessidade de usar o termo no plural, ou seja, de nos referirmos aos letramentos. Por quê?

1 Os assessores técnico-pedagógicos (ATPs) eram professores da rede estadual de educação que foram deslocados de sala de aula para desempenhar funções de apoio à Secretaria de Estado da Educação, incluindo atividades de gestão e formação.

2 Os professores coordenadores ( $\mathrm{PCs}$ ) eram aqueles que, além do trabalho em sala de aula, desempenhavam a função de coordenador de determinadas áreas ou disciplinas. 
A sociedade assiste, atualmente, à introdução de novas modalidades de práticas sociais de leitura e escrita, fomentadas e requeridas pelas recentes tecnologias de comunicação eletrônica: o computador e a internet - apenas para citar os mais emblemáticos. Aplicativos e ferramentas tecnológicas surgem e crescem, tornando a comunicação mais complexa. É preciso, então, analisar, definir e explicar novas práticas sociais em seu imbricamento com a leitura e a escrita de gêneros emergentes nas diferentes esferas da atividade humana. No que diz respeito aos trabalhos que visam proporcionar o desenvolvimento da leitura e da escrita - seja em sala de aula, sejam nas práticas de formação continuada de professores-, trata-se de promover "letramentos múltiplos, pois não há um texto-modelo que possa preparar para a compreensão e produção dos inúmeros textos que circulam socialmente" (Barbosa, 2007, p. 41, grifo do original).

Ao lado dessas novas práticas sociais de leitura e escrita, possibilitadas pelas tecnologias digitais, novas modalidades de comunicação - mediante imagem, som, vídeo e hipertexto - disputam espaço com a leitura e a escrita na produção dos discursos nas diferentes esferas da atividade humana. $\mathrm{O}$ fato de o $b i t^{3}$ ter se transformado na infraestrutura dessa nova comunicação multimodal e ter possibilitado a estruturação da sociedade em redes (Castells, 2006) levou vários autores a expandirem a expressão letramentos para além das fronteiras da leitura e da escrita, incorporando os conceitos de aquisição das habilidades e competências no manuseio das novas tecnologias assim como das práticas sociais decorrentes dessa aprendizagem. Dessa maneira, para autores como Valente (2008), Rangel (2009) e Maia (2011), o conceito de letramentos não se restringe à leitura e à escrita, pois abrange essas novas práticas sociais de comunicação multimodal e em rede possibilitadas pelo bit, ${ }^{4}$ que, segundo os autores, são compatíveis e correspondentes a novos níveis de tomada de consciência, autonomia e identidade do aprendiz. No entanto, por se basear em um curso de leitura e escrita desenvolvido por uma equipe de linguistas e especialistas na área, pautamo-nos, para esta pesquisa, no conceito mais amplamente aceito entre eles, ou seja, o conceito elaborado por Soares (1998) e Barbosa (2007).

$\mathrm{Na}$ direção do segundo conceito, consideramos mediação on-line o acompanhamento, a orientação e a articulação instigadora, feitos pelo professor, das trocas e construção de ideias entre os alunos por meio das ferramentas digitais (Rangel et al., 2008). Dessa forma, a mediação on-line encontra suas raízes nos conceitos de mediação, internalização e zona de desenvolvimento proximal (ZDP) de Vigotski (1991). Conforme aponta Oliveira (1993), a mediação realizada pelas pessoas próximas, com base em símbolos e significados social e historicamente construídos, é fundamental para o processo de internalização do indivíduo. O papel do professor consiste exatamente em mediar nessa ZDP, impulsionando o desenvolvimento. Ao ser on-line, o espaço de comunicação e mediação, descrito por Oliveira e Baranauskas

3 Bit é a unidade básica de informação dos sistemas computacionais de informação e comunicação.

4 Menor parcela de informação processada pelo computador. 
(1999), é constituído pelas interfaces computacionais dos ambientes virtuais utilizados no curso.

A mediação, ao ser on-line, implica o incentivo à presença cognitiva, social e de ensino (Garrison; Anderson; Archer, 2000) de todos os participantes para a construção de um sentimento, entre todos, de pertencimento ao grupo e ao processo de aprendizagem. Esse processo envolve a promoção de uma interação em múltiplas direções (mediador $\leftrightarrow$ aluno; aluno $\leftrightarrow$ aluno; aluno $\leftrightarrow$ conteúdo; aluno $\leftrightarrow$ ambiente; aluno $\leftrightarrow$ grupo; grupo $\leftrightarrow$ grupo etc.) e em diversos planos (didático-pedagógico, tecnológico, emocional, avaliativo, de gestão do curso e do ambiente), além das questões gerais, como o norteamento sobre a programação e as orientações didático-pedagógicas (esclarecimento de dúvidas, explicações, exemplificações etc.).

Nesse conjunto de interações três elementos básicos se articulam: presença cognitiva, relacionada à construção de significados pelos participantes do ambiente de aprendizagem; presença social, associada à projeção individual dos participantes no plano emocional e no plano social em relação aos outros participantes e, por fim, presença de ensino referente ao grau com que o professor concebe, planeja e facilita a aprendizagem.

Partindo dessas raízes teóricas, buscaram-se referências que se aproximassem das situações apresentadas em um curso de educação a distância (EaD). Baseadas nos trabalhos de Garrison, Anderson e Archer (2000), Garrison (2006), Barbosa et al. (2004) e nas reuniões periódicas de balanço e reorientação do curso, que envolviam a coordenação, os assistentes de coordenação e professores especialistas (PEs), as orientações do manual do Práticas, preparado para o encontro presencial de 30 de outubro de 2006, estabeleceram os parâmetros para que a mediação on-line se mantivesse vinculada às raízes teóricas sociointeracionistas, mas conservando a devida mobilidade e flexibilidade para sua transposição para o meio digital. Assim, ficou estabelecido que a mediação on-line no curso deveria ser caracterizada por quatro parâmetros fundamentais:

- Presença social. Por esse parâmetro o mediador deveria planejar e executar um conjunto de ações para que o aprendiz se sentisse acolhido pelo próprio mediador e por toda a turma da qual participava. Aspectos como afetividade, incentivo, apoio nas dificuldades, compreensão e paciência deveriam ser explicitados, presentes e frequentes nos quadros de avisos e nos fóruns.

- Interação em múltiplas direçôes. Implicaria acompanhar as dificuldades dos alunos buscando soluções e apoio em qualquer área que elas aparecessem; consistia também em aceitar alguns caminhos de debate sugeridos pelos participantes.

- Explicaçôes sobre a programação e os conteúdos. O cronograma e o conteúdo do curso deveriam estar sistematicamente à disposição dos alunos e acompanhados pelas explicações e mediações necessárias.

- Orientações didático-pedagógicas. Deveriam ser caracterizadas pelo esclarecimento de dúvidas, explicações teóricas, exemplificações, proposição de perguntas para estimular o debate na direção adequada etc. 
É importante ressaltar que o desenvolvimento das atividades, desde o início do curso, fez emergir um elemento não previsto inicialmente no design das aulas: a falta de tempo (Rangel, 2009) dos alunos para o pleno acompanhamento do curso. Esse elemento, apontado por todos os segmentos, incluindo os professores da Pontifícia Universidade Católica de São Paulo (PUC-SP), foi analisado em outros trabalhos como sintoma da arritmia entre as diversas aprendizagens e letramentos do curso, provocada pela ausência de habilidades, competências e letramentos capazes de desenvolver o volume de conteúdos do curso no ambiente virtual de aprendizagem e no ritmo inicialmente previsto. Por conseguinte, a falta de tempo aparecia como um elemento desestabilizador da mediação e dos letramentos constituindo-se em um possível fator de exclusão em relação ao curso.

Seguindo o objetivo do presente trabalho, os dois primeiros conceitos apresentados - letramentos múltiplos e mediação on-line - orientaram as etapas desenvolvidas na investigação, resgatando o que os mediadores traziam como bagagem, mas apontando também as lacunas e as novas exigências para uma mediação desejável em cursos on-line.

\section{O CONTEXTO DA INVESTIGAÇÃO}

O trabalho de pesquisa desenvolvido foi pautado no curso Práticas, que representou a concretização de uma política pública da Secretaria da Educação do Estado de São Paulo (SEESP) para formação de professores em serviço e configurou-se como um curso de aperfeiçoamento, com 260 horas, de responsabilidade do Programa de Pós-Graduação em Linguística Aplicada e Estudos da Linguagem da Pontifícia Universidade Católica de São Paulo (LAEL/PUC-SP).

O curso foi realizado a distância, sendo precedido por um módulo-piloto no primeiro semestre de 2005. Posteriormente, entre agosto de 2006 e julho de 2007, desenvolveu-se em seus quatro módulos. Como já explicitado, destinava-se à formação de ATPs, supervisores de ensino, PCs e professores de educação básica nível II e do ensino médio da rede pública do estado de São Paulo.

O Práticas foi financiado pelo Programa de Melhoria e Expansão do Ensino Médio (PROMED), por meio de convênio firmado entre a SEESP, o Ministério da Educação (MEC) e o Banco Interamericano de Desenvolvimento (BID). Visava ao desenvolvimento das habilidades e capacidades leitoras e escritoras para a ampliação do letramento geral e digital dos educadores, bem como à melhoria de sua formação profissional em relação ao trabalho de leitura e escrita com os alunos. Assim, o curso pautava-se no princípio de a leitura e a escrita serem um compromisso dos profissionais todas as áreas.

O curso contava inicialmente com uma equipe de coordenação, responsável teórica e institucionalmente pelo projeto, que supervisionava um grupo de seis assistentes, sendo estes professores doutores e mestres da PUC-SP, com formação nas áreas de linguagem e de $\mathrm{EaD}$. Além de oferecer apoio teórico-metodológico à coordenação, cada um dos assistentes era responsável por supervisionar e orientar os trabalhos de quatro PEs. Constituíram-se, então, seis equipes com um assistente de coordenação e quatro PEs de mesmo perfil dos assistentes, totalizando $24 \mathrm{PEs}$. 
Para atender às necessidades de formação dos 12.758 professores e PCs inicialmente inscritos, o Práticas foi estruturado em dois planos complementares.

No primeiro plano, o foco era a formação de 343 ATPs e supervisores que se inscreveram para, além de fazer o curso, atuar como mediadores on-line nas turmas de professores. Afora a formação sobre gêneros do discurso e aprimoramento das habilidades leitoras e escritoras em meios digitais, objetivava-se capacitá-los como mediadores on-line para que cada ATP pudesse repassar o mesmo curso mediando turmas, no segundo plano, compostas, cada uma, por 40 professores e PCs. Nesse segundo plano, focado na formação de professores e PCs, as turmas eram, portanto, mediadas pelos ATPs, que tinham seu trabalho supervisionado pelos PEs, seus mediadores no primeiro plano.

Assim, para responder à demanda de formação de mediadores on-line, cada $\mathrm{PE}$ assumia uma turma com 14 ATPs e/ou supervisores para ministrar o curso no primeiro plano. Dessa forma, a capacidade de formação do Práticas ficava vinculada à formação de 24 equipes com 14 ATPs cada uma, ou seja, 336 mediadores em formação. Como o curso teve a inscrição de 343 ATPs e supervisores, algumas turmas deveriam contar com mais de 14 participantes permitindo que, mesmo havendo algumas desistências, não se comprometesse o andamento geral do curso.

Esquematicamente a estrutura do primeiro plano do curso, com foco na formação dos 343 ATPs e supervisores inscritos, obedecia ao seguinte organograma, como mostra a Figura 1:

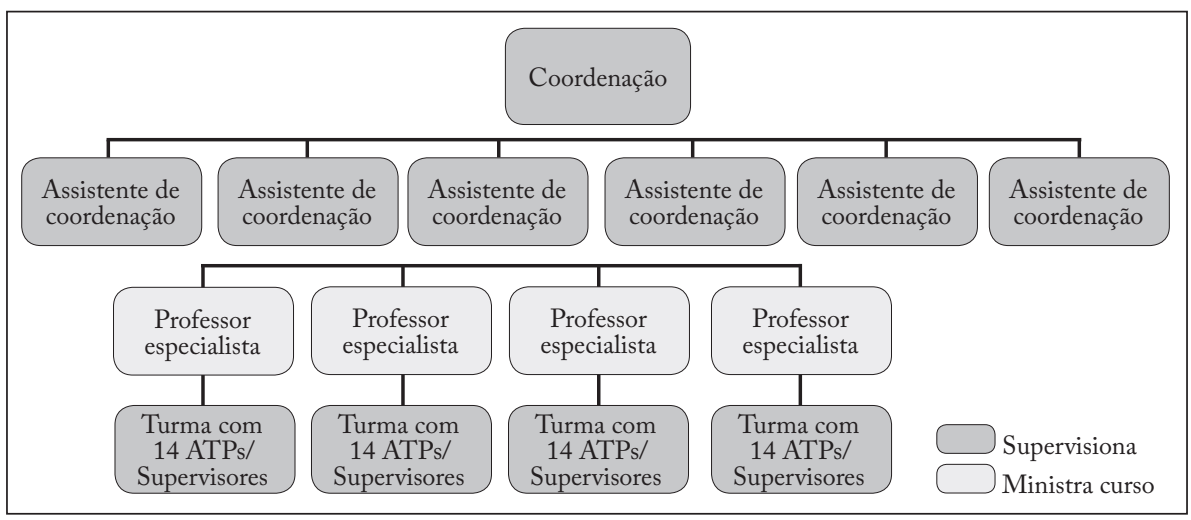

Figura 1 - Organograma do primeiro plano ${ }^{5}$ do curso Práticas.

Fonte: Banco de dados da pesquisa.

Elaboração dos autores.

No segundo plano, cada um desses 343 mediadores em formação (ATP ou supervisor) assumia uma turma de 40 professores e/ou PCs e era supervisionado pelo PE responsável pela sua formação no nível anterior. Contando com 343 mediadores e 40 professores em cada turma, seria possível atingir um limite 13.720

5 Formação de 343 ATPs e supervisores, organizados em 24 turmas, com 14 participantes em média, cada uma delas assistida por um PE, sob supervisão de um assistente de coordenação. 
professores em formação, mostrando uma estrutura capaz de atender, com certa folga, à demanda dos 12.758 inicialmente inscritos.

Nesse plano, com foco na formação dos 12.758 professores e PCs inscritos, a estrutura do curso seguia a organização esquematizada na Figura 2:

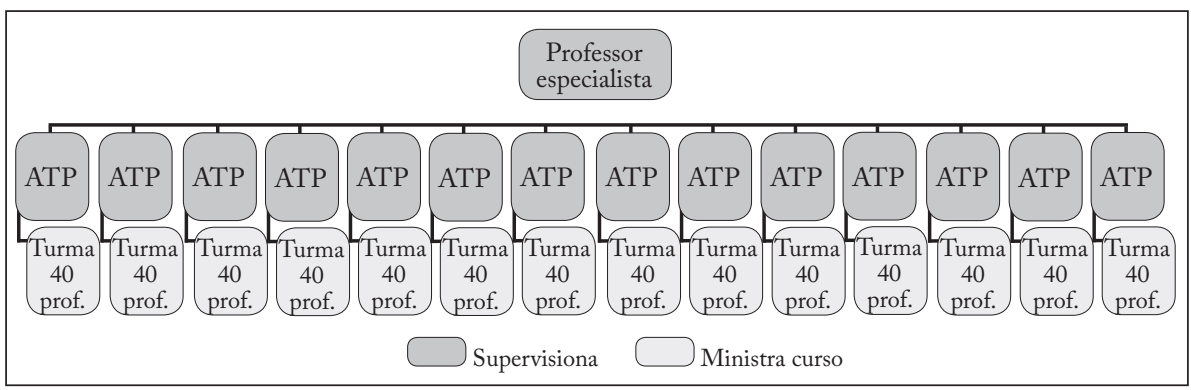

Figura 2 - Organograma do segundo plano ${ }^{6}$ do curso Práticas.

Fonte: Banco de dados da pesquisa.

Elaboração dos autores.

Do ponto de vista teórico-conceitual, o curso estruturou-se em concepções enunciativo-discursiva de linguagem (Bakhtin,1997) e sociointeracionista de aprendizagem e de mediação (Vigotski, 1991, 2001), e entre seus objetivos elencavam-se:

- Refletir sobre e exercitar as diferentes capacidades e competências leitoras e de produção de textos e de linguagens, envolvidas na recepção e na produção de discursos em diferentes gêneros que circulam em diversos contextos, suportes e mídias contemporâneos, com especial destaque para textos e discursos em gêneros de circulação na mídia digital (letramento digital), na esfera do jornalismo (impresso, televisivo, digital), na esfera das artes (literatura, música, cinema, artes plásticas) e na esfera escolar e da divulgação da ciência (em especial, nas áreas do conhecimento contempladas na divisão disciplinar da distribuição do conhecimento na escola, i.e., ciências da natureza, ciências humanas e área de linguagens e códigos);

- Refletir sobre a transdisciplinaridade inerente às práticas letradas de linguagem nos espaços sociais contemporâneos, de forma que possibilite a transformação da realidade disciplinar atual da escola;

- Refletir e avaliar as práticas de linguagem e de letramento correntes do alunado do ensino médio, a fim de esboçar propostas para o ensino mais condizentes com a realidade do alunado e que o encaminhem a práticas letradas cidadãs e contemporâneas.

A partir da conformação do contexto do curso, da definição de sua matriz teórica e do estabelecimento de seus objetivos, buscamos estabelecer os parâmetros metodológicos para a investigação que se anunciava.

6 Formação dos 12.758 professores e PCs, pelos ATPs, sob supervisão do PE. 


\section{ABORDAGEM METODOLÓGICA}

Como educadores, participávamos do curso de quatro formas distintas: contribuindo na elucidação das questões teóricas nas áreas específicas, na gestão pedagógica do curso durante os encontros presenciais, na formação/mediação dos professores e, finalmente, como pesquisadores, analisando os problemas que emergiam daquela prática social. Além de propor soluções que resolvessem aquela situação imediata e contribuíssem para a gestão, buscávamos, na teoria e na prática desenvolvida, análises mais aprofundadas que pudessem revelar novos elementos conceituais da mediação on-line. A investigação foi, então,

um tipo de pesquisa social com base empírica que é concebida e realizada em estreita associação com uma ação ou com a resolução de um problema coletivo e no qual os pesquisadores e os participantes representativos da situação ou do problema estão envolvidos de modo cooperativo ou participativo. (Thiollent, 2004, p. 14)

Dessa forma, a investigação foi caracterizada metodologicamente por:

- uma ampla e explícita interação entre pesquisadores, coordenação e professores em formação, interação essa que se deu ao longo de todo o curso durante a mediação das atividades e os encontros presenciais;

- um objeto de investigação - a mediação on-line - constituído por situações vivenciadas no curso e que denotavam dificuldades na sua continuidade, como as desistências; as atividades incompletas, realizadas superficialmente ou não realizadas; a baixa participação nos debates e as ausências recorrentes;

- objetivos da investigação estabelecidos para entender e discutir os elementos teórico-conceituais envolvidos na desistência dos mediadores para sugerir acomodações do curso;

- reuniões periódicas dos pesquisadores e especialistas com a coordenação e pelos dois encontros gerais, com a participação da coordenação, dos assistentes, dos PEs e dos ATPs e supervisores, para realinhamento dos trabalhos no curso;

- aumento do conhecimento e do letramento das pessoas envolvidas, tanto no curso quanto na investigação, tal como constava nos objetivos do curso.

Nesse contexto e pela abordagem metodológica, consideramos, para a seleção dos grupos de mediadores a serem estudados aqui, três conjuntos de critérios:

1) A organização e dinâmica do Práticas, focando:

- o desenho do curso, sua organização, dinâmica - seis circuitos compostos, cada qual, por um assistente de coordenação, responsável por quatro PEs, que ministravam o curso para de doze a quinze ATPs e/ou supervisores e que orientavam a mediação destes em suas turmas;

- a dupla função de cada ATP e supervisor: 
- a de aluno - ATPs e supervisores das diretorias de ensino do estado de São Paulo participavam do Práticas com o intuito de se aperfeiçoarem como professores de cursos on-line. Para isso, passavam pela experiência do curso como alunos, visando a sua formação como professores do módulo em questão (no total, houve quatro módulos);

- a de mediador - ATPs e supervisores (com as mais diversas formações) mediavam os módulos, já feitos como alunos, para um grupo de professores e/ou coordenadores da rede estadual (de todas as disciplinas). Essa tarefa exigia edição atualizada de quadros de avisos, abertura, acompanhamento e fechamento de fóruns, além de acompanhamento e avaliação das atividades dos alunos, e contava com orientação especial de PEs;

- a multiplicidade de fóruns propostos e desenvolvidos;

- as orientações dadas no encontro presencial, com ênfase na mediação. ${ }^{7}$

É importante notar que houve a seleção de um dos circuitos entre os seis, considerando aquele em que os pesquisadores deste trabalho estavam atuando.

2) O perfil dos ATPs e supervisores do circuito analisado, que se concentrou:

- na participação em todas as etapas previstas de mediação;

- na formação dos professores.

Considerando a questão-problema, foram selecionados dois ATPs ou supervisores de cada $\mathrm{PE}$ do circuito em questão, sendo um com formação em língua portuguesa e outro com formação em área distinta, respeitando a participação em todas as etapas previstas de mediação. Dessa seleção, foi constituído o Quadro 1:

Quadro 1 - Constituição da amostragem de pesquisa

\begin{tabular}{|c|l|c|l|c|l|}
\hline PE1 & \multicolumn{1}{|c|}{ Formação } & PE2 & Formação & PE3 & \multicolumn{1}{|c|}{ Formação } \\
\hline ATP1 & Matemática e pedagogia & ATP5 & Matemática & ATP9 & História \\
\hline ATP2 & $\begin{array}{l}\text { Pedagogia e biologia com } \\
\text { mestrado em educação }\end{array}$ & ATP6 & Pedagogia & ATP10 & Pedagogia \\
\hline ATP3 & $\begin{array}{l}\text { Letras: português } \\
\text { e espanhol }\end{array}$ & ATP7 & Letras: português & ATP11 & $\begin{array}{l}\text { Letras: português } \\
\text { e jornalismo }\end{array}$ \\
\hline ATP4 & Letras: português & ATP8 & Letras: português & ATP12 & Letras: português \\
\hline
\end{tabular}

Fonte: Banco de dados da pesquisa.

Elaboração dos autores.

7 Encontro presencial com os ATPs, realizado na sede da SEESP em 28 e 29 de setembro de 2006, para orientações gerais sobre gerenciamento, interação e mediação no curso, com caráter de workshop. 
3) As temáticas dos fóruns, consideradas no âmbito da problemática estabelecida para o estudo (comparação entre mediações de professores de língua portuguesa e professores de outras áreas).

O fórum que, a nosso ver, traria mais contribuições para a discussão deveria caracterizar-se por uma temática de cunho interdisciplinar e transversal, abordando questões de leitura e escrita. Por isso, entre os fóruns do curso, foi escolhido o "Ler e escrever devem ser um compromisso de todas as áreas?". Na abertura desse fórum, cada mediador lançava essa pergunta como um desafio para o debate entre os alunos.

Nas doze turmas, a sistematização das informações levantadas nas mensagens publicadas nesse fórum foi feita com a construção dos seguintes gráficos contrastivos entre os dois grupos de mediadores (com formação em língua portuguesa e com outras formações):

- Comparativo de mediação e participação;

- Comparativo de mediação desejável e não desejável;

- Comparativo de tipos de mediação desejável;

- Comparativo de tipos de mediação não desejáveis.

Para a definição das categorias de análise das mediações on-line, consideramos as mesmas que foram adotadas pelo curso. Baseado nas concepções enunciativo-discursiva de linguagem (Bakhtin, 1997), sociointeracionista de aprendizagem e mediação (Vigotski, 1991,2001) e nos princípios da colaboração on-line de Garrison (2006), o curso adotou as categorias propostas por Barbosa et al. (2004), a saber:

\section{Mediação desejável}

- Incentiva a participação de todos, a presença social, garantindo a todos os participantes o sentimento de pertencimento ao grupo;

- Promove a interação em múltiplas direções (e não só na professor $\leftrightarrow$ aluno), assegurando a construção coletiva do conhecimento e a presença de ensino;

- Favorece o desenvolvimento das atividades propostas conforme o programa e o cronograma previstos, permitindo, porém, certa flexibilização de acordo com o andamento do grupo;

- Oferece orientações didático-pedagógicas em quantidade, qualidade e momentos adequados, favorecendo a presença cognitiva.

Tipo 1: Mediação conceitual-problematizadora. Nessa categoria, o mediador

- Articula o próprio conhecimento à resposta do aluno;

- Considera o objetivo da questão, a compreensão do conteúdo, os principais elementos da resposta do aluno e as possibilidades de intervenção pedagógica.

Tipo 2: Mediação afetiva, fundamentada em papéis colaborativos. Com essa intervenção, o mediador 
- Preocupa-se com o estabelecimento de vínculos e/ou sentimento de pertencimento ao grupo.

Tipo 3: Mediação interativo-discursiva. Representa a atividade do mediador que

- Aponta imprecisões conceituais;

- Organiza/sumariza a discussão (elabora sínteses);

- Focaliza aspectos específicos, no intuito de chamar atenção dos alunos para o tema central da discussão;

- Identifica convergências e divergências.

Tipo 4: Mediação praxiológica. Nessa perspectiva, o mediador

- Convida à reflexão sobre a prática profissional, valendo-se do tema e/ou conceito em discussão.

\section{Mediação não desejável}

- É centralizada em papéis hierárquicos e na figura do professor;

- É pontual e em uma única direção (professor $\leftrightarrow$ aluno);

- Segue rigidamente o programa e o cronograma das atividades propostos, interrompendo a realização de uma atividade sem considerar o andamento do grupo;

- Oferece poucas orientações didático-pedagógicas em qualidade.

Tipo 1: Mediação conceitual-centralizadora. É pela qual o mediador

- Foca em seus próprios conhecimentos, sem considerar a resposta do aluno;

- Traz a resposta da atividade, excluindo a possibilidade de interação.

Tipo 2: Mediação descontextualizada. Nessa perspectiva, o mediador

- Não focaliza o objetivo da questão, tangenciando ou mesmo fugindo do conteúdo esperado.

Tipo 3: Mediação afetiva, fundamentada em papéis hierárquicos. Aqui a atuação do mediador

- Restringe-se a elogiar ou desqualificar a resposta, não possibilitando a interação objetivada na ferramenta.

Tipo 4: Mediação superficial-conclusiva. O mediador

- Repete a resposta dada, sem agregar contribuições que levam à reflexão adiante.

A classificação de cada mediação, em relação a essas categorias, foi realizada pelos professores doutores em linguística aplicada, que cumpriam a função de assistentes da coordenação. Os dados obtidos nos fóruns foram analisados com o 
apoio dessas categorias, tendo como referência a questão-problema. Serão apresentados e discutidos na próxima seção.

É importante observar que, coerentemente com os conceitos de letramento (Soares, 1998) e de letramentos múltiplos (Barbosa, 2007), as categorias de mediação contemplavam apenas aspectos intratextuais, ou seja, aqueles que só poderiam ser conferidos se fossem escritos pelos mediadores. No entanto, colocar uma imagem ou foto no ambiente virtual, um vídeo, um link, uma referência bibliográfica, um texto auxiliar, uma música, fazer a gestão sistemática do ambiente, também são ações de mediação e compõem o cenário discursivo juntamente com o texto, em sentido mais estrito. Essas habilidades mediadoras, tão importantes quanto o texto para a construção dos letramentos múltiplos em ambientes on-line, não foram plenamente contempladas nas categorias de análise adotadas, já que não se expressavam somente como texto escrito.

\section{RESULTADOS E DISCUSSÕES SOBRE A QUESTÃO-PROBLEMA}

Para a apresentação dos resultados nos pautamos pela amostragem de exemplos qualitativos de cada um dos tipos de mediação, seguidos pelo levantamento quantitativo das discussões sobre o conceito de mediação on-line e letramento e da retomada da questão-problema.

\section{COMPARAÇÃO ENTRE MEDIAÇÃO E PARTICIPAÇÃO}

Em um primeiro momento, procurou-se apresentar os dados concretos da efetiva participação dos dois grupos, buscando-se identificar se os professores com formação em língua portuguesa teriam publicado mais mensagens do que os com formação em outras áreas. Esse indicativo poderia ajudar a identificar uma tendência maior desses professores em relação à participação nos debates sobre gêneros discursivos (Bakhtin, 1997) nos fóruns e, por consequência, motivariam os alunos à maior presença social, de ensino (Garrison, 2006) e a uma mediação on-line (Barbosa et al., 2004) mais consistente, configurando um maior letramento (Soares, 1998) ou letramentos múltiplos (Barbosa, 2007) no trato dos gêneros discursivos em ambientes on-line.

O que se constatou, no entanto, foi que, embora a participação dos mediadores com formação em língua portuguesa fosse realmente maior, com mais presença social e de ensino (Garrison, 2006), a participação de seus alunos não diferiu muito, na média, em relação à dos alunos cujos mediadores tinham outras formações e não interagiram de forma tão frequente. Esses dados nos davam um indicativo de que aumentar a presença social, cognitiva e de ensino dos mediadores não seria, isoladamente, uma medida eficaz no combate à evasão apresentada no curso, já que o aumento da participação dos mediadores não tinha uma incidência direta no aumento da participação dos alunos. A mediação on-line e os letramentos múltiplos (Barbosa, 2007) pareciam mostrar graus maiores de complexidade. 


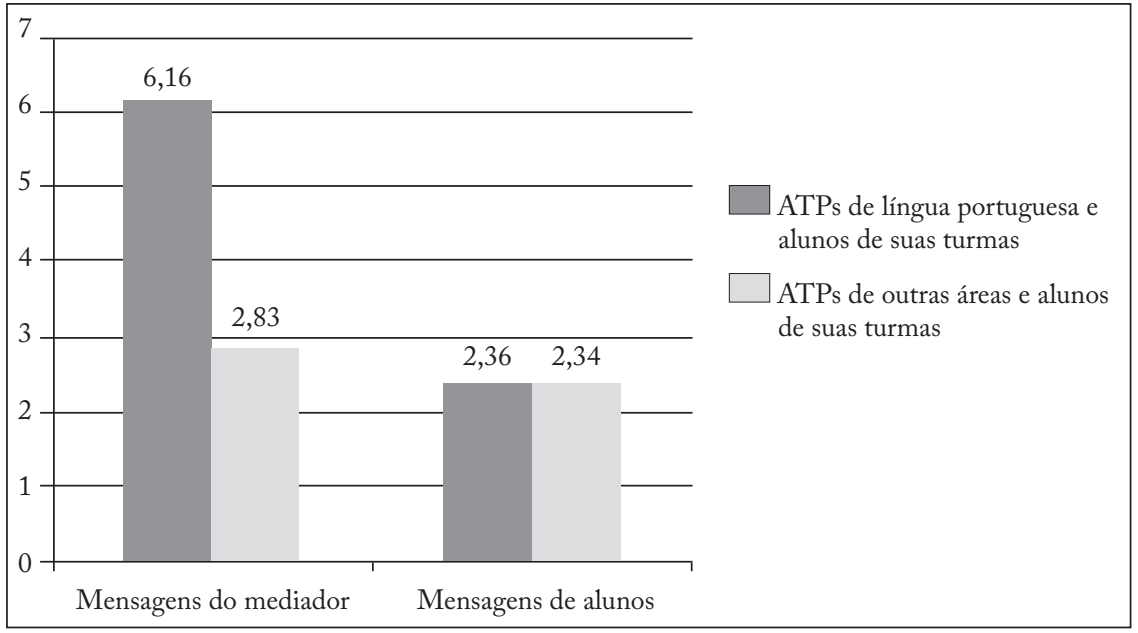

Figura 3 - Comparativo de mediação e participação.

Fonte: Banco de dados da pesquisa.

Elaboração dos autores.

\section{COMPARAÇÃO ENTRE MEDIAÇÃO DESEJÁVEL E NÃO DESEJÁVEL}

Do primeiro levantamento quantitativo de participação, partimos para um levantamento de dados qualitativos, tendo por base a diferenciação entre mediação desejável e não desejável (Barbosa et al.,2004), conforme categorização apresentada para os mediadores no encontro presencial de 28 e 29 de setembro de 2006. Embora o curso não tivesse estabelecido vínculos explícitos entre a categorização da mediação e os níveis de letramentos múltiplos, era possível supormos que a mediação desejável expressaria níveis mais avançados de letramentos múltiplos do que a mediação não desejável.

Do levantamento feito, chegamos aos dados da Figura 4:

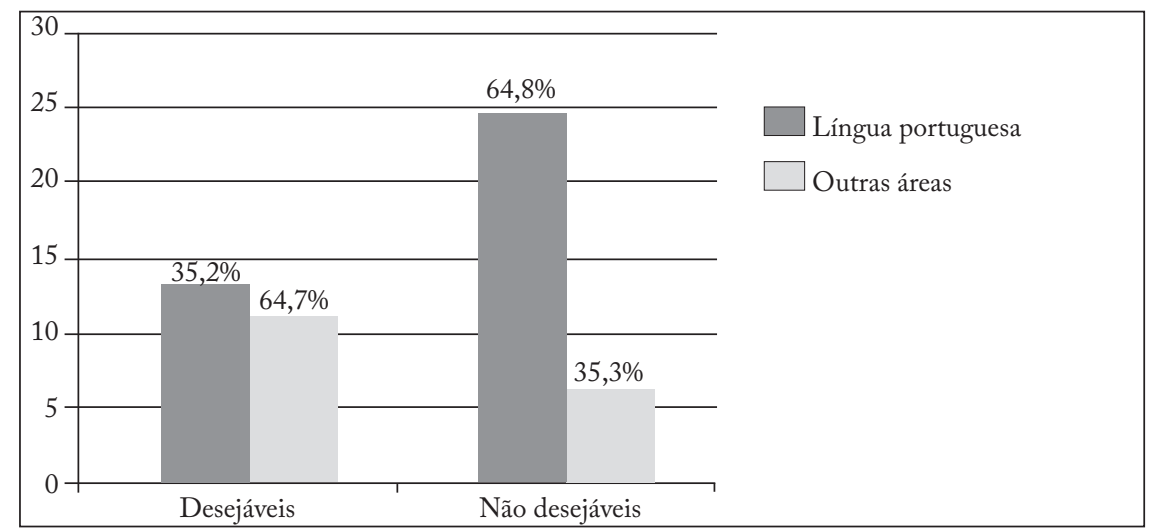

Figura 4 - Comparativo entre mediação desejável e não desejável.

Fonte: Banco de dados da pesquisa.

Elaboração dos autores. 
Os resultados contrariaram as nossas expectativas, pois, embora os mediadores com formação em língua portuguesa tenham mediado com maior frequência, isso não garantiu a qualidade desejável da mediação nem que expressassem maior grau de letramentos múltiplos (Barbosa, 2007). Já com os mediadores diplomados em outras áreas deu-se o contrário: mediações menos frequentes, porém com uma qualidade desejável maior, indicando um melhor desempenho nos letramentos múltiplos. Essa observação indicava que a qualidade da mediação, e não a quantidade, associada às habilidades e competências leitoras e escritoras no trato dos diversos gêneros discursivos em contextos de mediação on-line, contrariava a expectativa inicial de que, por serem especialistas em língua portuguesa, esses professores teriam um maior letramento, e, portanto, melhor desempenho na mediação.

Embora os conceitos de letramento (Soares, 1998) e de letramentos múltiplos (Barbosa, 2007) impliquem a existência de uma prática social letrada que, dada a atividade profissional, deveria ser mais desenvolvida nos professores de língua portuguesa, a qualidade da mediação on-line revelava que o domínio das habilidades leitoras e escritoras, por si só, não eram suficientes para determinar o desempenho social no uso da linguagem. Os resultados apontavam aspectos mais amplos dos letramentos, no plural, alertados por Valente (2008) e Rangel (2009), relacionados às habilidades e competências no uso dos recursos multimidiáticos, e não estritamente da leitura e da escrita, em situações discursivas nas práticas sociais.

\title{
COMPARAÇÃO ENTRE TIPOS DE MEDIAÇÃO DESEJÁVEL ${ }^{8}$
}

Para detalhar a mediação desejável nos dois grupos, utilizamo-nos dos tipos de mediação desejável, conforme categorização apresentada e exemplos a seguir:

\begin{abstract}
Mediação conceitual-problematizadora
Exemplo:

Êh povo arretado!!! Investigação, compreensão, habilidades, formação do professor, comparação, não decorar, letramento e assim por diante... Concordo e muito que a nossa formação não nos deu subsídios para encarar a metodologia que temos que aplicar e vivenciar. Os cursos superiores estão e devem estar passando também por uma reformulação - necessária - para que os novos profissionais não saiam de lá sentindo o que muito de nós sentimos. Percebemos que há uma dicotomia entre o real e o ideal [...]. Questão política, infraestrutura da escola, formação teórica dos alunos nas faculdades (futuros professores), novos conceitos, cursos que nos preparem e mostrem o "caminho das pedras", dimensão socializadora da prática da escrita e da leitura, entender os diversos estilos cognitivos, em classes mais que heterogêneas, aluno como sujeito da aprendizagem, professor mediando e instigando a formação desse discente, nos remete a outras questões: como a escola, como um todo, pode apresentar às nossas crianças o acesso ao mundo letrado? E nessa ação pedagógica, qual o papel
\end{abstract}

8 Os textos dos mediadores extraídos do fórum foram mantidos tal como foram escritos originalmente. 
dos professores na formação dos novos leitores e escritores nas diversas áreas do conhecimento? Beijos. (ATP 9)

\section{Mediação praxiológica \\ Exemplo:}

Conte mais para nós como a resolução de problemas de física está relacionada com a competência leitora. Essa parte interdisciplinar é ótima! (ATP 4)

\section{Mediação afetiva, fundamentada em papéis colaborativos}

Exemplo:

Gostei muitíssimo do texto que você postou. A alfabetização de jovens e adultos é possível ser feita através do incentivo à leitura, com o professor propiciando ótimos textos. Espero que os outros colegas leiam e debatam com você. $\mathrm{Pa}$ rabéns pela pesquisa! Beijos. (ATP 4)

\section{Mediação interativo-discursiva \\ Exemplo:}

Queridos, aproveitei o que vocês postaram e fiz a síntese: Ler e escrever é compromisso de todas as áreas CNMT, LCT e CHT. A linguagem escrita e oral permeia o conhecimento e as formas de conhecer, a comunicação e os modos de comunicar. O efetivo trabalho com a leitura e a escrita requer a integração entre todas as áreas, de maneira que realize a mediação no processo de ensino e aprendizagem e desenvolva nos alunos as competências e habilidades ao seu percurso. As dificuldades dos alunos nem sempre são para todos os textos, variam de acordo com o gênero, com a esfera a que pertencem. Os critérios usados para dizer que o aluno não sabe escrever, geralmente, referem-se à escrita sem coesão, coerência, ausência de sentido. Importante lembrar que, depois que o aluno se apropria da leitura e escrita, torna-se um indivíduo autônomo capaz de decidir suas próprias leituras e escritas. (ATP 11)

A Figura 5 registra os dados obtidos sobre a categorização de mediação desejável pelos dois grupos de mediadores.

A mediação praxiológica, independentemente da área de formação dos mediadores, foi a mais frequente. Isso pode se explicar pelo fato de o curso em andamento ter sido de formação continuada de professores e o foco na prática profissional ser comum e justificável. Os resultados sobre a mediação praxiológica indicavam um elemento de continuidade entre as práticas profissionais e a mediação e letramento em ambiente on-line.

Entretanto, causou estranhamento o fato de nenhum mediador de língua portuguesa ter publicado uma mensagem de cunho conceitual problematizador, já que, em princípio, teria mais bagagem e conhecimento em práticas de leitura e escrita. Esse aspecto indicou haver elementos de descontinuidade entre as práticas profissionais, a mediação e os letramentos em ambientes on-line. A expectativa era de que as mediações dos professores de língua portuguesa se destacassem qualitativamente na 


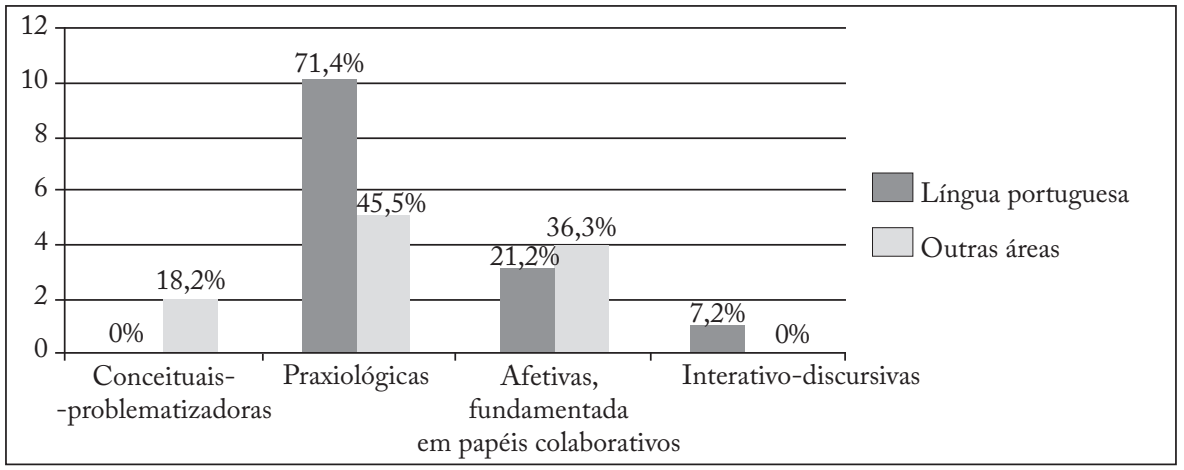

Figura 5 - Comparativo de tipos de mediação desejáveis.

Fonte: Banco de dados da pesquisa.

Elaboração dos autores.

área dos letramentos múltiplos (Barbosa, 2007), mas foram os professores de outras áreas que se sentiram mais à vontade no uso dos recursos multimidiáticos para problematizar os conceitos apresentados.

A familiaridade e o domínio em relação ao conteúdo e às práticas leitoras e escritoras podem ter atuado como inibidoras da exposição pública no ambiente, característica importante da mediação on-line, atuando como um elemento inibidor dos letramentos. Nesse caso, as habilidades e competências no uso dos recursos multimidiáticos (Rangel, 2009; Valente, 2008) e, consequentemente, a gestão dos graus de exposição on-line para cada situação de prática social de comunicação, aparecem como relevantes na explicação dos resultados.

As mediações afetivas, fundamentadas em papéis colaborativos, foram as que surgiram em segundo lugar de recorrência, independentemente da formação dos medidores. Isso revela uma forte tendência em se aproximar dos alunos, em transformar as interações em um convite à presença social, em um novo espaço para ambos.

Finalmente, na mediação interativo-discursiva destacam-se os mediadores com formação em língua portuguesa, provavelmente mais seguros para apontar inadequações, retomar conteúdos, articulá-los etc. Mesmo assim, o índice de frequência desse tipo de mediação pode ser considerado baixo, dada a temática do fórum, intimamente ligada à formação e à prática profissional de professores de língua portuguesa.

\section{COMPARAÇÃO ENTRE TIPOS DE MEDIAÇÃO NÃO DESEJÁVEL}

No segundo levantamento qualitativo, voltamo-nos para os tipos de mediação não desejável, que podem ser assim exemplificados:

\section{Mediação conceitual-centralizadora \\ Exemplo:}

Estou achando muito positiva a participação de vocês neste fórum, uma vez que estão argumentando suas respostas com base em suas experiências e nos excertos lidos na atividade. Perceber que a leitura deve ser um compromisso de todas 
as áreas, já que uma efetiva compreensão de textos supõe o desenvolvimento das capacidades de compreensão e de interação, e que no caso de textos ligados a certas áreas do conhecimento, dependem de um conhecimento específico, que o professor de outra área em geral não possui, é condição essencial para esta ação na escola. $\mathrm{O}$ professor de português pode e deve colaborar com os demais professores no sentido de levá-los a entender as capacidades em jogo, mas não pode se colocar como o único responsável pelo trabalho com leitura na escola, já que é impossível que ele domine todas as áreas do conhecimento. Abraços. (ATP 10)

\section{Mediação descontextualizada \\ Exemplo:}

Estou anexando novamente o cronograma final dos módulos e atividades que deverão ser cumpridas de acordo com a ordem contida nele. Favor observar a sequência. A nossa turma fará primeiro o módulo 4 (unidade 1 - atividade 1), depois o módulo 2 (unidade 1 - atividade 1) e por último o módulo 3 (unidade 1 - atividade 1). Este cronograma foi anexado nos fóruns dos grupos no dia 3/11/2006. Favor seguir rigorosamente este cronograma, que foi entregue pela CENP a todos os mediadores no encontro presencial, porém cada mediador e sua respectiva turma têm um cronograma diferente, que difere de diretoria para diretoria. Mediadora. (ATP 4)

\section{Mediação afetiva, fundamentada em papéis hierárquicos \\ Exemplo:}

Olá, pessoal! Vocês estão de parabéns pelas considerações importantes sobre a responsabilidade e os compromissos de todos na formação do aluno leitor. Estou muito feliz com a participação significativa de todos. Beijos. (ATP 4)

\section{Mediação superficial-conclusiva \\ Exemplo:}

Gostei da sua colocação, principalmente sobre seu trabalho em Geo. (ATP 11)

A Figura 6 sistematiza a categorização de mediação não desejável nos dois grupos.

Percebemos que a maior incidência de tipos de mediação não desejável recai nas descontextualizadas, tanto para os professores com formação em língua portuguesa quanto para os de outras áreas. Acreditamos que isso tenha acontecido porque grande parte do que se referia ao gerenciamento do curso (atividades) e do ambiente virtual foi feita nos fóruns, o que não estava previsto inicialmente. A fim de garantir a realização das atividades dentro do cronograma proposto, foi muito comum encontrar mensagens lembrando de prazos, explicando onde se encontrava esta ou aquela atividade, procurando alguém que estava distante do curso etc., em meio à discussão temática que se estabelecia. A mediação em múltiplas direções e planos parecia contribuir para a queixa da falta de tempo de todos os participantes e prejudicar a qualidade da mediação e dos letramentos em construção. 


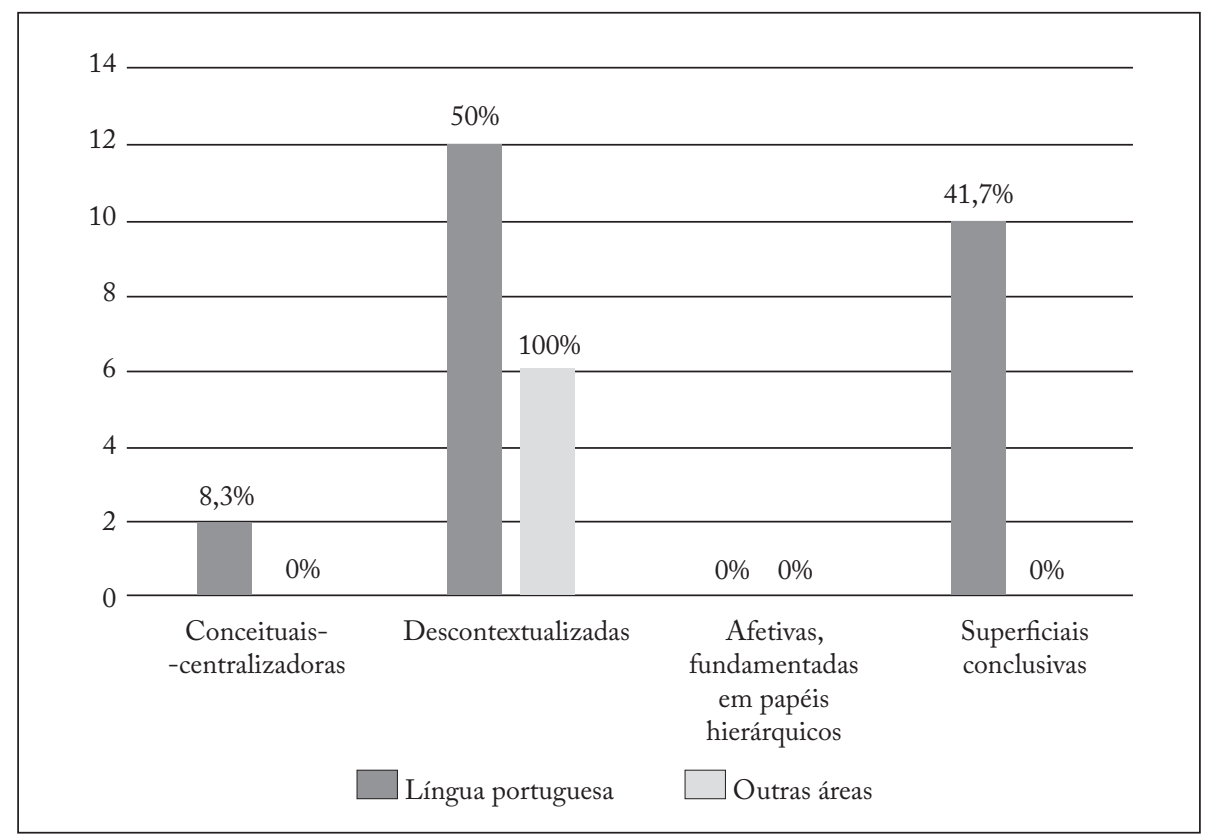

Figura 6 - Comparativo de tipos de mediação não desejável.

Fonte: Banco de dados da pesquisa.

Elaboração dos autores.

Os professores de língua portuguesa ainda apresentaram respostas conceituais-centralizadoras (talvez na ânsia de agilizar o andamento da discussão em razão dos prazos estabelecidos e da queixa geral de falta de tempo) e superficiais-conclusivas. Os professores das demais formações não se aventuraram em nenhuma das outras três direções. Novamente, o maior domínio dos conteúdos e a maior experiência nas práticas sociais letradas podem ter se constituído como dificuldades adicionais para os letramentos em ambientes on-line, apontando que os argumentos do debate entre letramento (Barbosa, 2007; Soares, 1998) de um lado, e letramentos (Maia, 2011; Rangel, 2009; Valente, 2008) de outro, são pertinentes e expressam diferentes características da realidade discursiva em ambientes on-line.

Dos dados revelados pela investigação podemos sistematizar os elementos centrais que deram base a nossas reflexões sobre a questão-problema:

- Os ATPs de língua portuguesa publicaram mais mensagens (em média) do que os ATPs de outras áreas, o que não significou melhor qualidade de mediação.

- Quanto aos tipos de mediação desejável, os ATPs de língua portuguesa publicaram prioritariamente mensagens praxiológicas. Os ATPs de outras áreas, por sua vez, dosaram suas mensagens entre as praxiológicas e as afetivas, baseadas em papéis colaborativos.

- Quanto aos tipos de mediação não desejável, os ATPs de língua portuguesa publicaram mais mensagens do que os de outras áreas, dividindo-as em descontextualizadas e superficiais-conclusivas. 
- Os ATPs de outras áreas, quando publicaram mensagens de tipos não desejáveis, restringiram-se às descontextualizadas (respostas às perguntas não relacionadas ao fórum ou às orientações de gestão).

- As interações entre os alunos não dependeram da mediação dos ATPs, fossem eles de língua portuguesa ou não. Essa constatação deu margem a uma nova investigação, atualmente em curso: como se caracterizou a interação entre os alunos, independentemente da mediação dos ATPs.

Diante da negativa encontrada como resposta à questão-problema - se os ATPs com formação em língua portuguesa teriam melhor desempenho como mediadores do fórum analisado -,e da análise construída com base nessa observação, sugerimos a retomada dos conceitos de mediação on-line e letramentos em um patamar que não se restrinja às habilidades leitoras e escritoras, mas que incorpore as habilidades e competências no trato dos recursos multimidiáticos.

\section{CONTRIBUIÇÕES PARA UMA POSSÍVEL REEDIÇÃO DO PRÁTICAS}

À guisa de contribuições para uma possível reedição do Práticas, a investigação realizada nos leva a sugerir, caso se continue tomando o fórum como espaço privilegiado de reflexão, que se considere:

a. A necessidade de explicitar os objetivos de cada fórum, indo além do que parece óbvio. No nosso caso, a abertura do fórum "Ler e escrever devem ser um compromisso de todas as áreas?" sugeria respostas simples, sem o estabelecimento de relações entre as diferentes áreas do conhecimento. $\mathrm{O}$ mediador/professor (de língua portuguesa) traz sua bagagem de experiência e conhecimento, mas não necessariamente tem desempenho compatível com o que já desenvolveu em leitura e escrita em sua formação. Em se tratando de um ambiente on-line, o tipo de mediação supõe um trabalho de formação de habilidades próprias a esse contexto para que as mediações tragam à discussão conceitos colocando os alunos em interação, e é importante que o tipo de mediação esperada fique explícito em cada atividade. Essa orientação se depreende da problematização dos conceitos de mediação on-line e letramentos, feitos no artigo.

b. A possibilidade de flexibilização de prazos de acordo com o ritmo e andamento de cada turma. As mediações voltadas ao gerenciamento do curso e do ambiente virtual reforçaram uma prática tradicional direcionada ao cumprimento estrito do programa e cronograma, o que não combina com ambientes digitais de aprendizagem que, por definição, precisam ser menos rígidos do que os presenciais, em razão do não sincronismo de trabalho por parte dos alunos. Se esses aspectos da mediação em múltiplas direções não forem contemplados, juntamente com a mediação dos conteúdos, como integrantes da mediação on-line, a falta de tempo surgirá como um forte elemento limitador da mediação e, por conseguinte, do aprendizado e dos letramentos a serem construídos. 
c. Os objetivos e contornos da mediação em cada fórum. $\mathrm{O}$ trabalho de orientação dos mediadores pode ser definido por meio de ações que os levem à preparação da atividade e não à sua execução. $\mathrm{O}$ que se quer com o fórum? Quais conceitos queremos acrescentar aos participantes? Qual síntese devemos fazer e em qual(quais) direção(ões) devemos ir? Essas são questões importantes que envolvem o conceito de mediação discutido no texto e que podem levar a equívocos por falta de foco, objetivo, clareza ou amplitude na proposta de mediação.

d. A eventualidade de conflitos e discussöes superficiais. Aprender a gerenciar conflitos, opiniões opostas não é algo simples e emerge como parte da mediação e dos letramentos on-line, mas de forma distinta da mediação dos letramentos sobre os conteúdos do curso. Sair do "achismo" ou das opiniões "generalistas" supõe reflexão e amadurecimento sobre o que se está trabalhando e reajustes conceituais para que esses fenômenos não sejam interpretados como estranhos ao curso, quando na verdade são parte indissociável da mediação e dos letramentos em ambientes on-line.

e. Odominio de escrita necessário (visto que a mediação on-line se baseia fortemente nela). Independentemente da formação, é importante que o mediador se sinta à vontade com a sua produção escrita para poder intervir sempre que achar necessário e fazer-se entender. Na mediação on-line isso significa estar disposto a um grau de exposição bem mais amplo que o habitual e de uma forma em que tudo fique registrado e exposto aos membros daquele ambiente virtual.

f. A qualidade da mediação. Quantidade, nesse contexto também, não é sinônimo de qualidade. É importante que as mensagens publicadas pelo mediador tenham consistência, sínteses, informações novas, questionamentos, e não apenas apelos à participação e/ou aos elogios a esta ou àquela resposta.

g. Oforte apelo de questöes praxiológicas em fóruns de cursos de formação continuada. Esse é um aspecto que pode ser aproveitado no design de cursos dessa natureza. Entretanto, é preciso cuidado para que as discussões que não têm um foco primordialmente praxiológico não resvalem para esse lado ocasionando um esvaziamento da discussão. $\mathrm{O}$ mediador precisa estar atento a esse tipo de estratégia, muito comum em grupos que trabalham na mesma área e que têm facilidade de fazer digressões em razão do pouco conhecimento no que se está trabalhando e na grande bagagem de experiência profissional que trazem. É preciso estar alerta para que os letramentos anteriores, construídos pelas práticas profissionais, não se constituam como um entrave à mediação on-line.

h. A importância das mensagens afetivas, baseadas em papéis colaborativos. É muito importante que os mediadores tenham consciência de que o reconhecimento de boas respostas, que revelam estudo, reflexão e pesquisa é algo que os alunos esperam. Entretanto, é necessário usar esse tipo de mensagem para articular várias respostas boas, nomeando seus autores, chamando outros para a discussão e apresentando novos questionamentos a partir delas. 
i. Um espaço definido para questóes de gerenciamento do curso. Usar o fórum para gerenciar o curso como um todo é uma estratégia que só deve ser adotada em último caso. O ideal é estabelecer, desde o início, um espaço em que fique claro para os alunos que eles precisarão frequentar para saber de prazos, atividades (inclusive as do fórum), dinâmicas de trabalho etc. Esse espaço pode ser a homepage do curso, um mural, e até mesmo um fórum, desde que este, especificamente, tenha essa função e que fique claro que é só nele que questões de gerenciamento serão apresentadas.

Para finalizar, gostaríamos de abordar dois aspectos que se destacaram durante a pesquisa e que apontam novos desdobramentos. Se observarmos os gráficos mais detalhadamente, é possível interpretar que as interações entre os alunos não dependeram necessariamente da mediação dos ATPs e supervisores. Olhando qualitativamente para o conjunto de mensagens do fórum investigado, percebemos contribuições muito boas, interações consistentes e argumentativas, independentemente da mediação feita. É hora, portanto, de analisar essas interações de alunos e buscar identificar o que fez com que elas acontecessem e como se constituíram, principalmente nos casos em que o mediador esteve ausente praticamente o tempo todo.

O segundo aspecto refere-se aos contornos dos conceitos de mediação on-line e de letramentos múltiplos. $\mathrm{O}$ fato de os professores de língua portuguesa, aparentemente mais preparados para um curso de práticas de leitura e escrita que os de outras áreas, não se terem destacado na mediação revela que a mediação e a construção dos letramentos múltiplos, por meio das tecnologias digitais, envolvem processos mais amplos e diferentes que os contidos no conceito adotado pelo curso.

\section{REFERÊNCIAS}

Bakнtin, M. Estética da criação verbal.2. ed. Tradução do francês por Maria Ermantina Galvão Gomes Pereira. São Paulo: Martins Fontes, 1997. Original de 1953.

Barbosa, J. P. Múltiplas linguagens: áreas do conhecimento no ensino fundamental. Brasil, Secretaria de Educação a Distância. Salto para o futuro. Brasília: MEC/SEED, Boletim, v. 18, p. 41-47, out. 2007. Disponível em: <www.tvebrasil.com.br/salto/ boletins2007/acef/index.htm>. Acesso em: 14 maio 2008.

.; Garcia, A. L.; Lopes, C. E.; Salgado, H. O.; Barbosa, L. M.; Ferreira, M. V.; Mendes da Silva, P. E. Interação aluno-professor em ambiente web: propondo categorias para análise do processo de ensino-aprendizagem. In: Simpósio Linguagem e Tecnologia como Mediadoras de Desenvolvimento, 14., 2004, São Paulo. Anais... São Paulo, Instituto de Pesquisas em Linguística Aplicada (XIV InPLA), 23 abr. 2004. Castells, M. A sociedade em rede. 9. ed. São Paulo: Paz e Terra, 2006.

Garrison, D. R. Online collaboration principles. Newburyport, MA: Editora Online Learning Consortium, v. 10, n. 1, Feb. 2006. Disponível em: <http://sloanconsortium. org/jaln/v10n1/online-collaboration-principles>. Acesso em: 22 out. 2012. 
.; Anderson, T.; Archer, W. Critical inquiry in a text-based environment: computer conferencing in higher education. The Internet and Higher Education, Florida, USA: Elsevier,v. 2, n. 2/3, p. 87-105,2000. Disponível em: <http://communitiesofinquiry. $\mathrm{com} /$ sites/communityofinquiry.com/files/Critical_Inquiry_model.pdf> Acesso em: 22 out. 2012.

MaIA,I.F. No jardim dos letramentos: tomadas de consciência e poéticas em rede na cultura da convergência. 2011. Tese (Doutorado em Artes Visuais) - Programa de Pós-Graduação do Instituto de Artes, Universidade Estadual de Campinas, Campinas, 2011.

Oliveira, M. K. Vigotski: aprendizado e desenvolvimento, um processo sócio-histórico. São Paulo: Scipione, 1993.

Oliveira, O. L.; Baranauskas, M. C. C. Interface entendida como um espaço de comunicação. In: Workshop sobre Fatores Humanos em Sistemas Computacionais, 2., Campinas, 17 a 19 out. de 1999. Disponível em: <http://www.unicamp.br/ ihc99/ Ihc99/AtasIHC99/art7.pdf >. Acesso em: 15 mar. 2003.

Rangel, F. O.; De-Angelis, C.; Martins, R. L.; Costa, H. Mediação pretendida ou possível? Uma questão de tempo. Revista Intercâmbio, São Paulo: Programa de Linguística Aplicada e Estudos da Linguagem da Pontifícia Universidade Católica de São Paulo, v. XVII, 2008, p. 177-192.

Mediação pedagógica em EaD: a falta de tempo como sintoma. 2009. Tese (Doutorado em Educação) - Programa de Pós-Graduação em Educação, Pontifícia Universidade Católica de São Paulo, São Paulo, 2009.

Soares, M. Letramento: um tema em três gêneros. Belo Horizonte: Autêntica, 1998.

Thiollent, M. Metodologia da pesquisa-ação. 13. ed. São Paulo: Cortez, 2004.

Valente, J. A. As tecnologias digitais e os diferentes letramentos. Revista Pátio, Porto Alegre: Grupo A, n. 44, nov./jan 2008. Disponível em: <http://www.revistapatio.com. br/sumario_conteudo.aspx?id=597 >. Acesso em: 15 jun. 2008.

Vigots кi, L. S. A formação social da mente. 4. ed. São Paulo: Martins Fontes, 1991. A construção do pensamento e da linguagem. São Paulo: Martins Fontes, 2001.

\section{SOBRE OS AUTORES}

Flaminio de Oliveira Rangel é doutor em educação pela Pontifícia Universidade Católica de São Paulo (PUC-SP). Professor da Universidade Federal de São Paulo (UNIFESP). E-mail: flaminio.rangel@unifesp.br

Heloisa Albuquerque Costa é doutora em letras pela Universidade de São Paulo (USP). Professora da mesma instituição.

E-mail: heloisacosta@uol.com.br 
Cristiane Cagnoto Mori De-Angelis é mestre em linguística pela Universidade Estadual de Campinas (UNICAMP). Professora da Pontifícia Universidade Católica de São Paulo (PUC-SP).

E-mail: de-angelis@uol.com.br

Roberta Lombardi Martins é doutora em linguística aplicada e estudos da linguagem pela Pontifícia Universidade Católica de São Paulo (PUC-SP). E-mail: roberta.1.martins@gmail.com

Recebido em novembro de 2012 Aprovado em dezembro de 2013 